\title{
PEMIKIRAN LIBERTY MANIK TERHADAP SEMANGAT NASIONALISME
}

\author{
Oleh : \\ Dra. Hafnita Sari Dewi Lubis, M.Si \\ Regina Siburian
}

\begin{abstract}
ABSTRAK
Penelitian ini bertujuan untuk mengetahui riwayat kehidupan Liberty Manik, keberadaan karya-karya Liberty Manik, pemikiran Liberty Manik dalam syair lagu dan tulisan serta semangat nasionalisme Liberty Manik. Untuk memperoleh data dalam penelitian ini, peneliti menggunakan metode penelitian Library Research (studi kepustakaan) dan field research (penelitian lapangan). Liberty Manik merupakan putra daerah kabupaten Dairi yang lahir pada tanggal 21 Nopember 1924 di desa Huta Manik, Kecamatan Sumbul Pegagan. Pada tahun 1940. Pengalaman batin akan peristiwaperistiwa pasca kemerdekaan telah mendorong Liberty Manik menciptakan sebuah lagu Satu Nusa Satu Bangsa yang bertujuan sebagai propogadis semangat kebangsaan seluruh masyarakat Indonesia. Semasa hidupnya Liberty Manik menciptakan tidak kurang dari enam lagu-lagu Indonesia, dua diantaranya bernafaskan nasionalisme yaitu lagu Satu Nusa Satu Bangsa dan Negara Jaya. Semangat nasionalisme Liberty Manik yang dituangkan ke dalam bidang musik sebagai seorang seniman menjadikannya menerima penghargaan Bintang Budaya Parama Dharma dari pemerintah Indonesia pada tahun 1999 .
\end{abstract}

Kata kunci : Liberty Manik, Semangat Nasionalisme 


\section{PENDAHULUAN}

Ketika suatu bangsa memutuskan untuk bersatu, nasionalisme atau paham kebangsaan merupakan suatu paham yang harus dan sangat dibutuhkan dalam menjaga eksistensi bangsa. Ide tentang kecintaan terhadap bangsa, yang kemudian sering disebut sebagai nasionalisme, lahir dari suatu buah pemikiran yang terus menerus yang kemudian memunculkan kesadaran berbangsa dan bernegara. Hakikatnya gerakan nasionalisme mempengaruhi munculnya ide-ide baru mengenai organisasi dan defenisi baru tentang identitas suatu bangsa seperti agama, sosial, politik dan ekonomi. Perwujudan ide semangat nasionalisme melahirkan sebuah fase sejarah khususnya di Indonesia, yang lebih dikenal dengan istilah kebangkitan nasional. Fase ini ditandai dengan kemunculan Boedi Oetomo pada 20 Mei 1908. Organisasi ini, dan organisasi yang muncul setelahnya bertujuan mencerdaskan bangsa berdasarkan kesadaran, tekad dan upaya memajukan bangsa atas dasar falsafah dan wawasan yang bersumber pada kepribadian nusantara, didukung para cendikiawan yang berbasis pada pendidikan nasional untuk melawan penjajah. Gerakan nasionalisme Eropa pada perkembangannya memberikan pengaruh yang besar terhadap perkembangan nasionalisme di kawasan Asia-Afrika, termasuk Indonesia. Jejak pengaruh nasionalisme Eropa yang masuk ke Indonesia, setidaknya terekam juga dalam khasanah musik. Pembentukan musik nasional terjadi ketika para pemuda Indonesia melakukan gerakan untuk membebaskan diri dari kaum penjajah Belanda serta gerakan menciptakan kebudayaan nasional. Gerakan yang terjadi pada tahun 1920-an di bidang musik tersebut mengarah kepada upaya untuk menciptakan musik yang tidak berciri etnis seperti sistem tangga nada slendro dan pelog pada ansambel gamelan.

Pada masa perjuangan melawan kolonialisme, perkembangan musik diatonik menjadi fenomena politik yang disebabkan oleh perbedaan pandangan tentang musik nasional. Perkembangan musik diatonik sebagai sarana pendidikan nasionalisme mengalir seiring munculnya generasi penerus setelah W.R Supratman dan Muhammad Syafei pendiri sekolah Indonesisch Nederlansche School Kayu Tanam di Sumatera 
Barat diantaranya, munculnya para pemusik daerah di Tapanuli dengan latar belakang pengetahuan musik gereja misionaris Jerman yang cukup handal. Adapun mereka antara lain, Cornel Simanjuntak, Amir Pasaribu, J.A Dungga, Binsar Sitompul, W. Lumban Tobing dan Liberty Manik. Para pemusik ini beranggapan bahwa musik nasional tidak boleh dibangun diatas budaya musik Jawa saja, musik diatonis lebih terbuka bagi umum di lapisan masyarakat dengan berbagai kebhinekaannya.

Satu dari pemusik yang disebutkan diatas adalah Liberty Manik, salah seorang pencipta lagu wajib nasional yang berjudul, "Satu Nusa Satu Bangsa”. Beliau berasal dari desa Huta Manik, Kecamatan Sumbul, kurang lebih 18 km kearah selatan ibukota Kabupaten Dairi (Kecamatan Sidikalang), Sumatera Utara. Penelitian ini bertujuan untuk mengetahui riwayat kehidupan Liberty Manik, keberadaan karya-karya Liberty Manik, pemikiran Liberty Manik dalam syair lagu dan tulisan serta semangat nasionalismenya.

Untuk memperoleh data yang dibutuhkan, peneliti menggunakan penelitian lapangan (field research) dan study pustaka (library research) yaitu dengan mengumpulkan data-data melalui wawancara dengan informan dan mengkolaborasikan dengan data-data yang diperoleh dari sumber tertulis lainnya.

\section{PEMBAHASAN}

\section{Riwayat Hidup Liberty Manik}

Liberty Manik adalah seorang putra daerah Dairi, Provinsi Sumatera Utara yang berasal dari desa Hutamanik, kecamatan Sumbul (kurang lebih 18 km ke arah selatan kecamatan Sidikalang), yang lahir pada tanggal 21 Nopember 1924. Dalam Bunga Rampai Dr. Liberty Manik, Liberty Manik dan ketiga saudara perempuannya (Sukut Manik, Jamu Manik, Harap Manik) lahir dari seorang ibu yang bernama Solat br. Situmorang dan seorang ayah yang bernama Patiham Manik. Liberty Manik lahir dari keluarga yang berstatus sosial yang baik. Patiham Manik menjabat sebagai Kepala Kampung Huta Manik. Patiham Manik mempunyai tiga isteri yaitu Diung br Padang, 
Solat br. Situmorang dan Annaria br. Simbolon sehingga Raja Patiham Manik dikarunia 11 anak yang terdiri dari 8 orang puteri dan 3 orang putera. Muntilan Manik mengatakan Liberty Manik adalah sosok parhata sada atau seseorang yang berkemauan keras Menurut penulis, pada masa kecilnya sudah tampak beberapa sifat yang menggambarkan kepribadian Liberty Manik yaitu seseorang yang percaya diri dan berjiwa bebas.

Sesudah menyelesaikan pendidikannya di HIS Sidikalang pada tahun 1940, beliau berkeinginan melanjutkan sekolah ke Pulau Jawa. Setelah lulus seleksi masuk HIK Muntilan beliau berangkat menuju Muntilan menggunakan kapal laut yang kemudian bertemu dengan Cornel Simanjuntak. Cornel Simanjuntak telah belajar satu tahun lebih dulu di HIK Muntilan. HIK Xaverius College Muntilan dikenal sebagai sekolah pendidikan guru dan menempatkan musik sebagai salah satu kegiatan ekstrakurikuler yang pokok dalam kegiatan pembelajaran siswa. Kedatangan Jepang ke Indonesia pada tahun 1942 menyebabkan sekolah HIK Muntilan terpaksa ditutup karena guru-guru yang berkebangsaan Belanda harus pulang jika tidak ingin ditawan Jepang. Hal tersebut menyebabkan siswa-siswa tidak bisa melanjutkan sekolah dan tidak bisa pulang kampung apalagi bagi siswa-siswa perantau. Jikalau Cornel Simanjuntak bekerja menjadi pengajar di sekolah dasar di Magelang, Liberty Manik menjadi penyanyi dan pemain biola pada siaran Radio Semarang ( Semarang Hoyokyooku).

Hidup dijaman pasca kemerdekaan menjadi pengalaman yang tidak pernah bisa dilupakan begitu saja. Liberty Manik yang ketika itu masih sebagai pemuda turut merasakan bagaimana kolonial dan pendudukan Jepang berusaha merusak kemerdekaan Indonesia yang baru saja diperoleh. Belanda dengan politik memecah belahnya dan Jepang dengan propaganda 3A mencoba menggoncangkan kesatuan Indonesia yang baru saja dinyatakan melalui Proklamasi Kemerdekaan. Pengalaman batin tersebut menggugah Liberty Manik untuk menciptakan suatu lagu yang berjudul Satu Nusa Satu Bangsa yang bertujuan mengikat kemajemukan Indonesia menjadi satu. 
Dengan harapan lagu tersebut bisa menjadi suatu doa guna menopang kemerdekaan tersebut.

Pada tahun 1954, Lembaga Kerjasama Kedutaan Indonesia- Belanda (Sticusa) mengundang Liberty Manik untuk belajar musik dari seorang komponis Belanda, Kees Kef di Amsterdam. Kemudian pada tahun 1955, Liberty Manik berangkat menuju Wuppertal-Barmen untuk mempelajari Musik Gerejawi pada "Landeskirchen Musik Schule im Rheinland" atas undangan dari Rheinische Missions Gesellschapt (RMG) dan sekarang berubah nama menjadi Vereinigte Evangelische Mission (VEM). Pada akhir tahun 1959, atas dukungan Kedutaan Besar Repubik Indonesia di Bonn, Liberty Manik memperoleh beasiswa dari Deutscher Akademi Scher Austavschdienst (DASA) untuk melanjutkan studinya ke Freie Universitat di Berlin Barat.

Dalam kegiatan surat-menyurat yang dilakukan Liberty Manik kepada keponakannya, Singotan Situngkir sejak tahun 1970 hingga tahun 1993 baik sedang di dalam negeri maupun di luar negeri, diketahui bahwa Liberty Manik adalah seorang yang rajin membaca. Beberapa kali dalam suratnya Liberty Manik meminta agar dikirimi buku-buku lama seperti buku Tilhang Gultom tentang Opera Batak, Alkitab (Bibel) berbahasa Angkola, Pustaha Taringot tu Tarombo Nihalak Batak, buku karya Waldemar Hutagalung, dan sebagainya. Jikalau beberapa bagian dari fotocopyan buku tersebut masih kurang lengkap, beliau akan menyurati kembali agar segera dikirimkan lanjutannya hingga lengkap sepenuhnya. Bahkan sampai tahun 1991 beliau masih selalu meminta agar dikirimkan buku-buku lama. Dalam suratnya tahun 1970, beliau mengatakan “ Sebetulnya seseorang (Indonesia) tidak dapat disebut Sarjana kalau tidak menguasai paling sedikit satu bahasa asing, seperti Jerman atau Perancis". Pernyataan tersebut tampaknya bertujuan agar setiap mahasiswa Indonesia siap sedia menghadapi peluang di masa yang akan datang. Liberty Manik yang sering dikenal sebagai komponis merupakan sesorang intelektual yang gigih belajar dan selalu haus memperluas wawasannya, baik dalam bidang ilmu yang ditekuninya maupun isu-isu yang berkembang di masanya. 
Liberty Manik meninggal dunia di Rumah Sakit Bethesda Yogyakarta setelah beberapa hari dirawat disana akibat menderita pendarahan usus dan diketahui melalui aktivitas saling mengirim surat dengan Situngkir, keponakannya, Liberty Manik sudah mengalami sakit-sakitan dimulai tahun 1981 hingga akhir hayatnya di tahun 1993. Setelah upacara adat batak dilaksanakan pada tanggal 17 September 1993 di kediamannya Melati Glondong, Jalan Magelang Km 8 Sleman, Yogyakarta, jenazahnya disemayamkan di Aula Institut Seni Indonesia Yogyakarta. Acara penghormatan terakhir kepada Liberty Manik dilakukan dengan melantunkan konser lagu Satu Nusa Satu Bangsa, Desaku, Pantai Sepi dan lagu-lagu gereja kesukaan beliau. Pemakaman Liberty Manik dihadiri staff pengajar, mahasiswa ISI, anggota paduan suara, keluarga almarhum yang datang dari Sumatera Utara, pejabat daerah, seniman Saptohaedoyo beserta istri dan handai taulan. Turut juga Dirjen Kebudayaan Depdikbud. Liberty Manik dimakamkan di Taman Makam Seniman Imogiri, Bantul Yogyakarta beserta dengan seniman-seniman Indonesia lainnya.

\section{Keberadaan Karya- Karya Liberty Manik}

Manik memaparkan selama revolusi banyak sekali lagu-lagu perjuangan yang timbul di Indonesia bagai jamur di musim hujan. Sebagian besar dari lagu-lagu tersebut bersandar pada cita-cita kemerdekaan yang sedang diperjuangkan dan pada umumnya diterima baik dan digemari semua lapisan masyarakat. Tidaklah mengherankan bila masyarakat Indonesia sangat haus pada lagu-lagu yang menjanjikan cita-cita kemerdekaan bagi nusa dan bangsa. Hal itu mendorong seniman-seniman dalam lapangan masing-masing.

Tidak sedikit dari mereka, terutama angkatan muda yang telah mengayunkan pena dan pensilnya dengan mengambil motif-motif dari perjuangan yang sedang bergejolak disekelilingnya. Diantaranya adalah Cornel Simanjuntak dan Liberty Manik, seniman muda Indonesia di bidang musik yang mewujudkan rasa cinta tanah airnya dengan turut menaruh perhatian akan peristiwa yang terjadi di sekelilingnya melalui gubahan lagu. 
Liberty Manik tidak banyak menciptakan lagu-lagu Indonesia bila dibandingkan dengan komposer lainnya. Ciptaan Liberty Manik tidak kurang dari enam lagu, yaitu Satu Nusa Satu Bangsa, Desaku Yang Kucinta, Pantai Sepi, Di Laut, Tamanku dan Negara Jaya. Disamping itu, beliau aktif menerjemahkan lagu-lagu rohani rakyat daerah Simalungun, Pakpak dan Karo serta lagu rohani yang berasal dari Eropa. Sampai sekarang ini lagu Satu Nusa Satu Bangsa sebagai salah satu lagu wajib nasional masih tetap dikumandangkan terlebih sebagai sarana upacara. Sementara lagu Desa Ku Yang Kucinta kerap kali dinyanyikan dan diajarkan di bangku Taman KanakKanak hingga Sekolah Dasar guna memupuk kecintaan akan kampung halaman. Sedangkan lagu yang berjudul Pantai Sepi, Di Tamanku, Di Laut, merupakan karya dari perenungan personal (kesadaran diri) pencipta. Serta lagu yang berjudul Negara Jaya masih kurang akrab di kalangan masyarakat Indonesia, hal tersebut dikarenakan lagu tersebut belum sempat diperdengarkan kepada publik oleh pencipta.

Menurut Situngkir, Liberty Manik menciptakan lagu Desa Ku Yang Ku Cinta dan Pantai Sepi antara tahun 1945-1950. Sedangkan lagu yang berjudul Di Laut, Tamanku tidak diketahui secara pasti kapan Liberty Manik menciptakannya. Namun, Situngkir memprediksikan lagu-lagu tersebut diciptakan sekitar tahun 1945-1950 juga. Hal tersebut selaras dengan penuturan Liberty Manik pada tahun 1972 saat diundang wawancara di RRI Medan, yang mana beliau sama sekali tidak menciptakan sebuah lagu pada saat menetap di Eropa. Kemudian, Situngkir memaparkan lagu yang berjudul Negara Jaya adalah lagu yang terakhir kali ditulis menjelang wafatnya Liberty Manik sehingga tidak sempat dipublikasikan. Partitur dan lirik lagu tersebut ditemukan diantara tumpukan dokumen-dokumen Liberty Manik setelah dipindahkan dari kediamannya di Yogyakarta ke Medan.

\section{Pemikiran Liberty Manik Dalam Syair Lagu Dan Tulisan}

Pemikiran dapat diartikan sebagai suatu ide atau gagasan yang melahirkan hasil karya yang diperuntukan bagi masyarakat. Liberty Manik yang dikenal sebagai pencipta lagu 
Satu Nusa Satu Bangsa tidak hanya menciptakan lagu namun juga menulis berbagai artikel di majalah yang terbit dimasanya seperti majalah Zenith.

Syair ataupun lirik lagu merupakan suatu rangkaian pesan yang diuraikan dari sebuah konsep dengan sekumpulan gagasan, citra dan praktik yang menyediakan cara-cara untuk mengatakan sesuatu atau menyampaikan sesuatu. Lirik lagu merupakan representasi pencipta tentang bagaimana dunia dikonstruksi dan disajikan kepada publik sebagai penikmat seni selain guna memperlihatkan eksistensinya dan menyampaikan realitas dimasanya. Dalam hal ini, peneliti akan menginterpretasikan lirik lagu-lagu hasil karya Liberty Manik guna memahami ide maupun buah pemikirannya.

Berikut lagu-lagu ciptaan Liberty Manik tersebut (Tim Penyusun, belum terbit :4650) adalah sebagai berikut :

\title{
Satu Nusa Satu Bangsa
}

Satu nusa satu bangsa satu bahasa kita

Tanah air pasti jaya untuk selama-lamanya

Indonesia pusaka Indonesia tercinta

Nusa bangsa dan bahasa

Kita bela bersama

Salah satu karya ciptaan Liberty Manik yang sangat dikenal masyarakat Indonesia adalah lagu wajib nasional "Satu Nusa Satu Bangsa". Menurut Liberty Manik lagu Satu Nusa Satu Bangsa diciptakan pada tahun 1947 di suatu tempat disamping keraton Yogyakarta. Berdasarkan salah satu pemaparan karya dari Liberty Manik, dapat dilihat bahwa karya lagunya yang berjudul Satu Nusa Satu Bangsa merupakan lagu yang menggambarkan semangat nasionalisme. Hal tersebut dapat dilihat dari isi dan makna lagu yang berkaitan dengan tajuk lagu-lagu rakyat, bahwa lagu tersebut membentuk suatu kesatuan terhadap rakyat dan bangsanya.

\author{
Desa Ku Yang Ku Cinta \\ Desaku yang kucinta, pujaan hatiku \\ Tempat ayah dan bunda dan handai taulanku \\ Tak mudah ku lupakan \\ Tak mudah bercerai
}




\section{Selalu ku rindukan}

Desaku yang permai

Menurut Situngkir dalam dokumennya pada tahun 1994, salah satu karya dari Liberty Manik yang berjudul Desaku Yang Ku Cinta merupakan sebuah lagu kenangan yang diciptakan pasca kemerdekaan Indonesia sekitar tahun 1945-1950. Lagu tersebut menggambarkan tentang kecintaan pencipta terhadap kampung halaman, tempat (seseorang) dilahirkan yang tidak bisa dilupakan. Tampaknya pencipta mengingatkan kembali setiap individu agar dimana pun berada saat ini tetap mengingat kampung halamannya.

\section{Pantai Sepi \\ Tiba dari jauh, ombak mengeluh \\ Pada pantai yang sepi \\ Sorak nan lesu sayu menderu \\ Pada pantai yang sepi \\ Ombak menderu ratapan hatiku \\ Riuh berseru pada mu \\ Pantai yang sepi \\ Tempat berhenti, ombak hati yang sedih}

Berdasarkan salah satu pemaparan karya dari Liberty Manik, dapat dilihat bahwa lagunya yang berjudul Pantai Sepi merupakan lagu yang menggambarkan kesedihan. Lirik lagu tersebut menceritakan tentang suatu perisitiwa yang melanda diri seseorang akan kesedihan hati dalam jiwa dan pikiran nya yang di halusinasikan terhadap sebuah pantai. Dalam mengetahui pesan sebuah lagu terdapat beberapa komponen yang bisa diterima dan ditangkap oleh indera manusia yaitu lirik, musik, pengarang dan lain sebagainya. Penulis melakukan interpretasi terhadap lirik lagu yang diciptakan komponis guna mengetahui pesan dan makna yang ingin disampaikan kepada pendengar.

\section{Di Laut}


Cahaya terang indah cemerlang

Di laut cahaya terang

Ombak menderu bersorak merdu

Dilaut ombak menderu

Memutih layar terkembang, melancar bidukku kencang

Terus ke depan, terus ke depan

Tak akan kembali kawan

Gembira kawan maju ke depan

Di laut gembira

Selanjutnya salah satu pemaparan karya dari Liberty Manik, dapat dilihat bahwa lagunya yang berjudul Di Laut merupakan lagu yang menggambarkan tentang kepercayaan diri seseorang untuk menatap masa depan, yang di landasi oleh rasa semangat yang kuat dan rasa ingin maju terhadap diri seseorang.

\title{
Tamanku \\ Indah dalam taman, bunga berseri \\ Harum bertaburan tidak berperi \\ Alam pun bersuka, sinar cemerlang \\ Aman dan sentosa, damai dan tenang \\ Taman pujaanku indah dan permai \\ Hiburan hatiku susah bercerai \\ Ikhlas dan setia aku berseru \\ Kau tetap ku jaga taman negeriku
}

Selanjutnya salah satu lagu yang merupakan karya Liberty Manik yang berjudul Tamanku merupakan lagu yang girang dengan tempo lambat. Penulis menginterpretasikan lagu tersebut merupakan sebuah penggambaran kekaguman (pencipta) terhadap sesuatu. Pada lirik baris yang pertama hingga baris yang ke enam merupakan pernyataan kekaguman yang dilakukan secara berulang-ulang dengan penggambaran objek yang berbeda sementara pada baris yang ketujuh hingga baris terakhir merupakan sebuah penegasan kembali yang ditandai dengan adanya sebuah janji.

\author{
Negara Jaya \\ Mari kawan semua bangkit bersama \\ Seia dan sekata bahu membahu \\ Tujuan kita negara yang jaya
}




\section{Tugas mulia ada ditanganmu}

Bagi nusa dan bangsa kerahkanlah tenaga

Jabarkan Pancasila teguhkan persatuan

Gembira, gembira menuju bahagia

Gembira, gembira menuju bahagia

Menurut Situngkir lagu ini adalah lagu terakhir yang ditulis oleh Liberty Manik menjelang hayatnya. Keseluruhan lirik lagu tersebut mengisyaratkan suatu harapan akan nusa dan bangsa, menjadi sebuah seruan persuasif yang bersemangat kepada masyarakat Indonesia agar bersatu padu memewujudkan suatu negara yang jaya dengan berdasarkan nilai-nilai yang terkandung dalam Pancasila sebagai ideologi negara Indonesia. Berdasarkan salah satu pemaparan karya dari Liberty Manik, dapat dilihat bahwa lagunya yang berjudul Negara Jaya merupakan lagu yang menggambarkan tentang semangat nasionalisme yang diperuntukkan bagi persatuan bangsa Indonesia.

Sebagai seorang komponis, Liberty Manik bisa dikatakan tidak cukup produktif melahirkan lagu-lagu Indonesia. Jika dilihat dari sisi jumlah karya yang diciptakan, beliau menciptakan tidak kurang dari enam lagu. Dua dari lagu tersebut, lagu yang berjudul "Satu Nusa Satu Bangsa", dan "Negara Jaya" adalah lagu yang bernafaskan semangat nasionalisme. Sementara empat lagu yang lain adalah lagu-lagu perenungan personal yang dihalusinasikan dengan keindahan alam dan lingkungan.

Dalam tulisan-tulisan beliau dalam "Musik di Indonesia dan Beberapa Persoalnnya" dan majalah Zenith edisi tahun 1953, sebagaimana karya yang berhasil dihimpun pihak keluarga, terdapat beberapa tulisan hasil buah pemikiran Liberty Manik disamping juga oleh beberapa pemusik lain seperti Amir Pasaribu dan Binsar Sitompul serta Sitor Situmorang dibidang seni sastra. Dalam tulisan tersebut peneliti memahami bahwa Liberty Manik adalah seorang yang tidak saja bertalenta di bidang seni permainan musik tetapi juga dibekali pengetahuan yang luas tentang musik (intelektual musik).

\section{Semangat Nasionalisme Liberty Manik}


Nasionalisme muncul dan berkembang sesuai dengan sejarah dan pengalaman bangsa dalam mencintai bangsa dan negara sendiri. Munculnya kesadaran akan keterbelakangan posisi dan deskriminasi yang ada diantara masyarakat Indonesia pada masa kolonialisme telah melahirkan suatu keinginan untuk bebas dan merdeka. Citacita merdeka dan membentuk negara sendiri dinyatakan setelah masyarakat mengenal pendidikan dan mulai membentuk suatu organisasi yang kemudian melahirkan ide-ide baru hingga pada akhirnya berhasil menyatakan kemerdekaan Indonesia.Namun ketika Indonesia merdeka pada tahun 1945, nasionalisme Indonesia mengalami ujian baru saat Belanda kembali melancarkan agresinya dengan politik devide et impera( memecah belah) masyarakat guna mengguncang kesatuan negara Indonesia yang baru merdeka.

Semangat nasionalisme sebagai suatu kesadaran cinta tanah air, bangga menjadi bagian dari Indonesia, dan menempatkan kepentingan bersama diatas kepentingan pribadi telah merasuk juga dalam bidang seni dimana para senimanseniman seperti Liberty Manik turut mewujudkan rasa cinta tanah airnya dengan menciptakan lagu yang bertujuan mengikat kebhinekaan masyarakat menjadi satu. Berdasarkan berbagai sumber tertulis dan wawancara dengan informan, Liberty Manik menciptakan enam lagu-lagu Indonesia seperti yang telah disebutkan diatas, disamping juga turut menggubah lagu-lagu gerejawi.

Lagu sebagai sebuah karya seni dicipta selain untuk ekpresinya, tetapi seni tercipta karena seniman sendiri memiliki kebutuhan berinteraksi dan berkomunikasi dengan masyarakat atas konsep, ide, serta gagasannya, artinya ada sebuah pesan yang hendak disampaikan melalui karya ciptanya tersebut. Begitu pula pesan lagu disampaikan oleh penciptanya bukan hanya sekedar memusikalisasi puisi atau pesan, atau mempuitisi sebuah bentuk musikal tetapi lebih jauh ia ingin mengemukakan totalitas kedalaman jiwa hasil dari perenungannya. Sehingga bukan hanya sekadar terjadinya sebuah komunikasi yang komunikatif tetapi komunikasi lagu yang terjadi ketika makna, tema, pesan dari lagu dapat tersamppaikan kemudian dihayati, dimaknai, oleh pendengar sehinggga dapat merubah sikap dan perilaku. Ketika perilaku komunikasi berubah setelah dilakukannya komunikasi, maka disitulah hakikat 
komunikasi lagu terjadi, yaitu terciptanya sebuah nilai perubahan. Demikian halnya dengan lagu-lagu yang diciptakan para komponis Indonesia pada masa perjuangan.

Dalam syair lagu Satu Nusa Satu Bangsa terdapat buah pemikiran nasionalisme yang ditunjukkan dengan kalimat "satu nusa satu bangsa, satu bahasa, tanah air pasti jaya untuk selama-lamanya”, dan ide atau pemikiran ini tetap terulang kembali dalam lirik lagu yang berjudul Negara Jaya “Tujuan kita negara jaya...bagi nusa dan bangsa kerahkanlah tenaga, jabarkan Pancasila teguhkan persatuan”. Dalam lagu gubahan Liberty Manik terdapat semangat nasionalisme Indonesia seperti yang tercantum dalam Pancasila, khususnya sila ketiga yaitu Persatuan Indonesia. Ide persatuan Indonesia tersebut tampak dalam karyanya yang fenomenal "Satu Nusa Satu Bangsa" dan "Negara Jaya". Persatuan Indonesia ditandai dengan rasa cinta tanah air, bangga menjadi bagian dari bangsa dan masyarakat Indonesia, menempatkan kepentingan bersama diatas kepentingan pribadi ataupun kelompok, mengakui dan mengahargai keanekaragaman yang ada di Indonesia, ikut memajukan dan mengharumkan nama Indonesia serta membangun rasa persaudaraan.

Dalam Suara Pembaruan tahun 1992, Liberty Manik menegaskan sikapnya bahwa dalam menciptakan lagu Satu Nusa Satu Bangsa merupakan murni suatu pengabdian, sehingga karya tersebut lahir sebagai dunia yang benar-benar dijalani dan dihayatinya, bukan karena ditunjuk oleh suatu pihak. Kemudian beliau menegaskan bahwa dalam menciptakan lagu dibutuhkan pengalaman batin dan tidak bersifat sembarangan. Selanjutnya, Liberty Manik menyatakan sikapnya yang tidak akan menciptakan lagu-lagu yang dikomersialkan seperti yang lazim dilakukan para musisi. Pengalamannya dalam menciptakan lagu menyebabkan bahwa materi bukanlah tujuan.

Dalam tulisannya di berbagai media cetak, seperti yang telah diterbitkan Balai Pustaka pada tahun 1952, Liberty Manik menaruh perhatian yang besar terhadap musik di Indonesia dengan berbagai persoalannya. Keahliannya di bidang musik telah mendorong Liberty Manik untuk turut menyumbangkan buah pemikirannya tentang musik dalam tulisan-tulisan tersebut guna bisa memberikan pemahaman baru dalam seni musik, sebagai contoh dalam tulisannya yang berjudul, Indonesia Raya Dilihat 
Dari Dekat, Sekitar Musik Di Indonesia, Sekitar Lagu-Lagu Dalam Revolusi dan sebagainya.

Sebagai seorang seniman yang ikut meningkatkan, memajukan dan membina kebudayaan nasional sesuai dengan Peraturan Pemerintah Republik Indonesia Nomor 12 Tahun 1986 Tentang Tanda Kehormatan Bintang Budaya Parama Dharma, Presiden Indonesia, Bacharuddin Jusuf Habibie menganugerahkan Piagam Tanda Kehormatan Bintang Budaya Parama Dharma kepada Liberty Manik sebagai “Guru Musik” pada tahun 1999. Pemberian tanda kehormatan berupa bintang kepada warga negara Indonesia adalah untuk menghargai jasanya yang besar yang telah diberikan terhadap nusa, bangsa dan negara dalam bidang kebudayaan.

Sementara untuk mengenang dan menghormati jasa dan pengabdian Liberty Manik di daerah kelahirannya, warga Dairi atas prakarsa Bupati Kepala Daerah Tingkat II Dairi Drs. S. Isodorus Sihotang membangun sebuah "Monumen Liberty Manik” di Daerah Wisata Letter S Desa Sitinjo Kecamatan Sidikalang.

\section{III.PENUTUP}

Berdasarkan hasil penelitian dan pembahasan yang telah dilakukan maka diperoleh kesimpulan bahwa, Liberty Manik sebagai salah seorang putra daerah Dairi yang lahir pada tanggal 21 Nopember 1924 di desa Hutamanik, Kecamatan Sumbul Pegagan merupakan seseorang yang mandiri, disiplin, berpendirian teguh, tegas dan cerdas. Keberangkatannya untuk belajar di H.I.K Xaverius College Muntilan setelah lulus ujian termasuk ujian bahasa Belanda, mempertemukannya dengan Cornel Simanjuntak. Belajar di H.I.K Muntilan memberikan pengalaman baru bagi Liberty Manik, baik dalam perkembangan pengetahuannya di bidang musik juga pembentukan karakter Liberty Manik yang mendapat pengaruh dari Barat.

Selama tinggal di Yogyakarta, Liberty Manik turut merasakan dan melihat peristiwa-peristiwa pasca kemerdekaan Indonesia, ketika Belanda melancarkan serangan agresi yang pertama. Pengalaman batin dimasanya telah mendorong Liberty Manik menciptakan sebuah karya, Satu Nusa Satu Bangsa yang menjadi ide pemersatu 
keanekaragaman yang ada di Indonesia. Semasa hidupnya, beliau menciptakan enam buah lagu-lagu Indonesia disamping itu juga turut menggubah lagu-lagu gerejawi.

Dalam lagu gubahan Liberty Manik terdapat semangat nasionalisme Indonesia seperti yang tercantum dalam Pancasila, khususnya sila ketiga yaitu Persatuan Indonesia. Persatuan Indonesia ditandai dengan rasa cinta tanah air, bangga menjadi bagian dari bangsa dan masyarakat Indonesia, menempatkan kepentingan bersama diatas kepentingan pribadi ataupun kelompok, mengakui dan menghargai keanekaragaman yang ada di Indonesia, ikut memajukan dan mengharumkan nama Indonesia serta membangun rasa persaudaraan. Ide persatuan Indonesia tersebut tampak dalam karyanya yang fenomenal "Satu Nusa Satu Bangsa" dan "Negara Jaya". Karakter dan kepribadian Liberty Manik sangat kuat. Ditandai dengan penuturannya yang tidak akan menciptakan lagu-lagu yang untuk diperjualbelikan. Pengalaman dalam menciptakan lagu menyebabkan bahwa materi bukanlah tujuan.

\section{DAFTAR PUSTAKA}

Dungga, dan Manik. 1952. Musik di Indonesia dan Beberapa Persoalannya. Balai Pustaka : Jakarta.

Gottschalk, Louis. 2008. Mengerti Sejarah. Universitas Indonesia Press: Jakarta.

Harahap, Syahrin. 2014. Metodologi Studi Tokoh dan Penulisan Biografi. Prenada : Jakarta.

Huen, Lim Pui, dkk. 2000. Sejarah Lisan Di Asia Tenggara. LP3ES : Jakarta.

Kartodirdjo, Sartono.1999. Pengantar Sejarah Indonesia Baru Sejarah Pergerakan Nasional Dari Kolonialisme Sampai Nasionalisme Jilid 2. Gramedia Pustaka Utama : Jakarta.

Koentjaraningrat. 2004. Kebudayaan Mentalitas dan Pembangunan. Gramedia : Jakarta.

Koentowijoyo. 2003. Metodologi Sejarah. Tiara Wacana Yogya : Yogyakarta 
Ricklefs,M.C. 1999. Sejarah Indonesia Modern. Gajah Mada University Press : Yogyakarta.

Sidjabat, W. 1968. Partisipasi Kristen Dalam Nation Building di Indonesia. BPK : Bandung.

Simanjuntak, Payaman. 1992. Seniman Pejuang dan Pejuang Seniman. HIPSMI : Jakarta.

Sirait, H. 2007. “Cornel Simanjuntak-Sekali Berarti Lalu Mati”. Tatap Nomor 4.

Sjamsuddin, Helius. 2012. Metodologi Sejarah. Ombak: Yogyakarta.

Soedarsono,R.M. 1998. Seni Pertunjukan Indonesia di Era Globalisasi. Direktorat Jenderal Pendidikan Tinggi Departemen Pendidikan dan Kebudayaan : Jakarta.

Soekarno. 1963. Dibawah Bendera Revolusi Jilid I. Jakarta.

Tim Penyusun. Belum Terbit. Bunga Rampai Dr. Liberty Manik. Sidikalang 